\title{
Structural Features of the Refractory Powder Materials Based on Titanium Carbide Obtained by SHS-Grinding
}

\author{
Z.T. Turganov*, A.M. Stolin, P.M. Bazhin, O.A. Averichev \\ A.G. Merzhanov Institute of Structural Macrokinetics and Materials Science Problems of RAS, \\ 8, Academician Osipyan ul., Chernogolovka, 142432, Russia \\ * Corresponding author. Tel.: +7 49652463 95. E-mail: Zangar.turganov@mail.ru
}

\begin{abstract}
The paper presents the experimental study results of the powder refractory materials morphology of the Ti-C system obtained by SHS grinding in a closed reactor. The micro- and macrostructure is considered, the values of the dispersion of the powder are given depending on the grinding modes of the synthesis products. Under optimal grinding conditions, roundshaped titanium carbide with a fineness of 20-60 microns was obtained. The content of the oxide phase in the titanium carbide powder decreases from 2 to 9 times with increasing grinding intensity, and does not exceed 5 mass. \%
\end{abstract}

\section{Keywords}

SHS processes; SHS grinding; sintering; shear high-temperature deformation.

(C) Z.T. Turganov, A.M. Stolin, P.M. Bazhin, O.A. Averichev, 2020

\section{Introduction}

For the practice of SHS processes, of great interest is the question of the hot synthesis effect on mechanical deformation of products at the stage of the finely divided powder structure emerging. Preliminary theoretical and experimental studies show that deformation parameters and, above all, deformation intensity, have a significant effect on the morphology, dispersion and degree of coagulation of grains during the formation of large globular particles [1]. Fundamental differences in the mechanisms and dynamics of structure formation in SHS processes under mechanical stresses pose new challenges in the field of structural macro kinetics of chemical transformations [2].

As a rule, the role of mechanical effects during shear deformations consists in mixing the powder and in ensuring a uniform temperature distribution over the volume of the material, as a result of which the morphological homogeneity of the material increases $[3,4]$. On the other hand, the occurrence of large shear stresses during mechanical deformation positively affects the final structure of the powder material: cracks and pores are "healed", grains are crushed, and as a result, the strength and ductility of materials increase
[5]. The implementation of these mechanisms is based on the ability of the hot mass of the synthesized product to macroscopic deformation. During SHS grinding of powders of refractory compounds, the hot porous material is compacted under the influence of external pressure, a structural skeleton is formed from individual particles, and sintering and hardening of the combustion products during cooling are intensively carried out [6]. As intergranular contact expands, the process of grain coalescence develops. The development of this process depends on the presence of a fluid that separates adjacent grains, as well as the action of internal and external forces. Under the experimental conditions, various sintering mechanisms can be implemented: sintering under the action of only internal forces (acts until the external pressure is implemented) and sintering under the external pressure applied (from the start of grinding to the end of the process) [7].

The competition of sintering mechanisms against the background of cooling of the combustion products determines the non-monotonic nature of the dependence of the crushed mass of products on the time of application of mechanical stresses. This means that under optimal conditions, the course of post-processes 
Characteristics of the starting powders

\begin{tabular}{llccc}
\hline Powder & $\begin{array}{c}\text { Powder } \\
\text { grade }\end{array}$ & $\begin{array}{c}\text { National Standard (GOST), } \\
\text { Tachnical Specification (TU) }\end{array}$ & $\begin{array}{c}\text { Content of the basic substance } \\
\text { is not less than, \% mass. }\end{array}$ & $\begin{array}{c}\text { Particle size of the main } \\
\text { fraction is less, microns }\end{array}$ \\
\hline Ti (titanium) & PTM & TU-14-1-3086-80 & 45 \\
C (soot) & PM-15TC & OST-38-1531-73 & 1 \\
\hline
\end{tabular}

(sintering, compaction, cooling) should provide the minimum strength of the material, favorable for its grinding. With an increase in the delay time (the time interval between the initiation of combustion and the beginning of the application of the load), the material can acquire such strength that complete grinding will be impossible [8]. Thus, one of the key issues of conducting SHS under mechanical stress is the choice of such values of time parameters at which the maximum yield of the crushed powder occurs.

The aim of this work was to study the effect of shear high-temperature deformation on dispersion, morphology, and the degree of homogeneity of titanium carbide-based powder during SHS grinding in a closed reactor. For this, it is necessary to determine the grinding modes at which the yield of the crushed product is maximum and contains a minimum amount of undesirable impurities.

\section{Objects of research and experimental technique}

As the object of study, a Ti-C charge system of stoichiometric composition 1:1 was chosen. This choice is due to the heat and wear resistance of coatings based on titanium carbide, high hardness, resistance to aggressive environments, so that powders based on it are quite actively used in modern industry. To prepare the mixture the following powders of industrial production are used (Table 1).

Preparatory operations (drying, dosage, mixing) were carried out according to the following scheme. The powders were loaded into containers with a layer height of $2-3 \mathrm{~cm}$ and preliminarily dried in ovens at a temperature of $60-80{ }^{\circ} \mathrm{C}$ for $6-8$ hours. The soot was dried at a temperature of $100-120^{\circ} \mathrm{C}$ for $2-3$ hours, the height of the bulk layer was $4-5 \mathrm{~cm}$. The dried powders were dosed on a VLTK-2 technical balance, providing a weighing accuracy of $0.1 \mathrm{~g}$. The charge was mixed in ball mills at the ratio of the mass of the mixture and the mass of the balls $1: 3.5$. Balls with a diameter of 8-30 mm made of stainless steel 12X18H10T were used. Mixing was performed at atmospheric pressure and room temperature for 24 hours. The rotation speed of the drum is $0.56-0.65 \mathrm{rpm}$. Next, the powders were placed in an oven to remove the remaining moisture and dried for 4 hours. For experiments with precompressed charge stock, tablets were used with a height of $18 \mathrm{~mm}$, a diameter of $25 \mathrm{~mm}$, and a weight of 20 grams. The pressing pressure was $5 \mathrm{MPa}$. A compressed tablet, or a sample of bulk density, was previously placed in a steel glass made of steel $45 \mathrm{X}$ of the SHS-grinding reactor with a filling of $0.3-0.4$ of its nominal volume (Fig. 1).

In the case of a bulk density sample, a pre-mixed charge was poured with a height of $30 \mathrm{~mm}$ and compacted to a height of $0.8 \mathrm{~h}$ beginning. A tungsten spiral initiated a combustion wave with a voltage of $U=40 \mathrm{~V}$, ignition was carried out from below. After the passage of the combustion wave, a rotor was fed to the lower base of the steel cup with a delay time of 0 to $15 \mathrm{~s}$, in increments of 5 seconds. The grinding lasted for 40-60 s until complete passage of the structural transformations in the synthesized charge. The experiments were carried out at rotor frequencies of 450 and $600 \mathrm{rpm}$. A general view of the installation is shown in Fig. 2.

The powders obtained as a result of the experiments were studied on a MicroSizer 201 laser particle size analyzer, a JEOL JSM 6430F scanning electron microscope, and a Difrey 401 compact X-ray diffractometer.

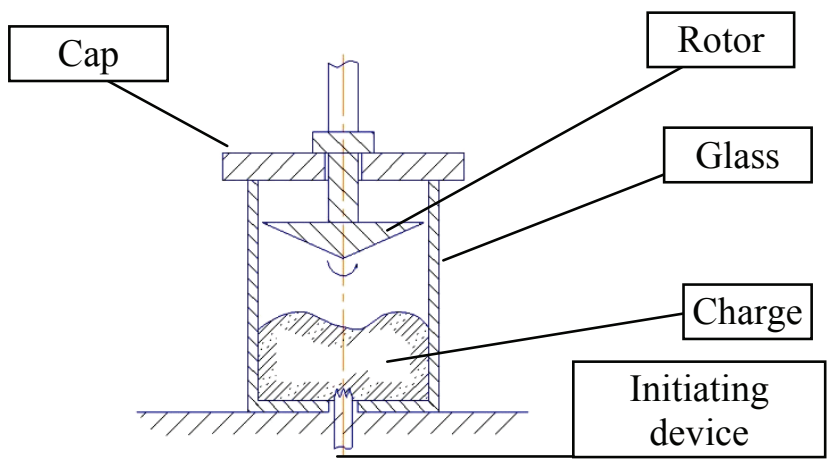

Fig. 1. SHS grinding reactor of a closed type 


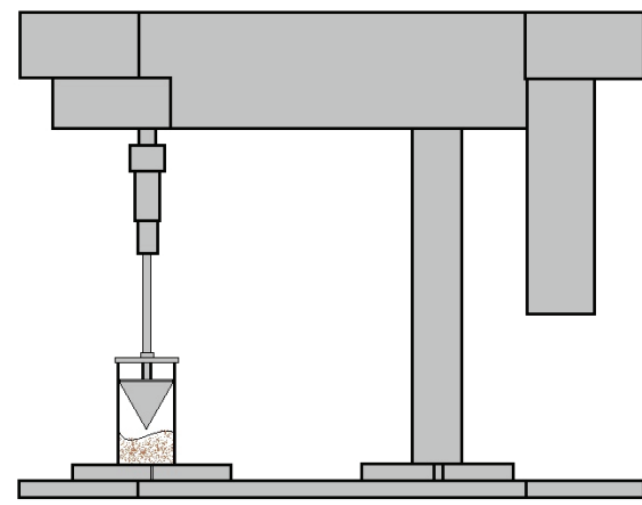

Fig. 2. A schematic diagram of the SHS-grinding installation

\section{Results and Discussion}

The SHS process takes seconds and the granulometric composition of the synthesized material and morphology are greatly influenced by parameters such as the delay time before applying mechanical deformation, its intensity and duration. Using the optimal parameters of SHS grinding, it is possible to achieve the most complete formation of the target phase with maximum dispersion of the powder. It was experimentally shown that the competition of sintering mechanisms against the background of cooling of the combustion products determines the non-monotonic nature of the dependence of the crushed mass of products on the delay time before applying mechanical influences. It was also established that after the SHS without the application of mechanical influences, the synthesized material consists of cake and for its subsequent grinding requires efforts significantly exceeding the capabilities of laboratory mechanized equipment. In a powder obtained by the SHS without mechanical influences, $\sim 95 \%$ of the particles have a size of more than 1000 microns, that is, the synthesis product is sintered and large particle agglomerates. When mechanical influences after the SHS are applied to a cold synthesis product, the number of agglomerated particles decreases, but their fraction is still high: at a weight fraction of $P=90 \%$, the particle size $D=600-1000 \mu \mathrm{m}$.

\section{Study of the influence of mechanical stress parameters on the dispersion of a hot synthesized material based on $\mathrm{TiC}$}

The delay time before the application of mechanical stresses has a significant effect on the yield of dispersed powder. Under optimal conditions, the course of post-processes (sintering, compaction, cooling) provides the minimum strength of the material, favorable for its grinding. Without mechanical influences, as well as when the delay time $t_{\mathrm{d}}$ is exceeded above the critical value, the material is hardened to such an extent that its grinding will be impossible.

The dependence of the product yield upon the SHS grinding of the bulk density of the Ti-C system bulk density depending on the rotor speed without delay $\left(t_{\mathrm{d}}=0 \mathrm{~s}\right)$ is shown in Fig. 3. It should be noted that even for the case of bulk density weighed, which is considered in the framework of this section, SHS without mechanical influences cannot ensure the dispersion of the powder $D<1000 \mu \mathrm{m}$ under any conditions. The diagram shows that the most complete dispersion of the cake occurs at a rotor speed of $600 \mathrm{rpm}$, while a non-monotonic dispersion distribution is observed depending on the rotor speed.

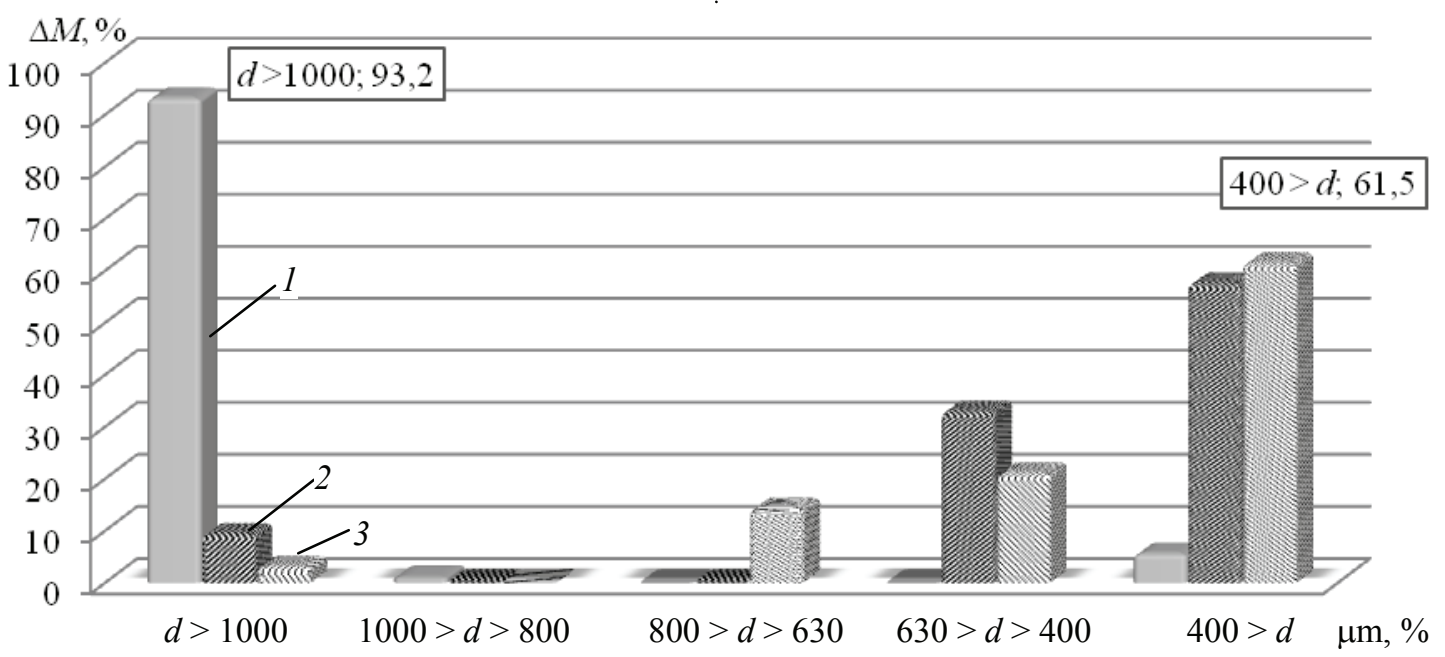

Fig. 3. The dependence of the crushed product yield on the rotor speed

1 - without mechanical stress alpplication; $2-450 \mathrm{rpm} ; 3-600 \mathrm{rpm}$ 
The dispersion distribution of the powder with the parameter $D<400 \mu \mathrm{m}$ was studied on an ultrasonic particle analyzer, a diagram of the correspondence of the weight fractions of particles $P$ to the given particle size ranges $D$ was obtained. In particular, at $P=70 \%$, $D<50 \mu \mathrm{m}$, the weight fraction for $D<20 \mu \mathrm{m}$ does not exceed $10 \%$ (Fig. 4).

From the obtained dependence of the dispersed powder yield on the grinding intensity, it was concluded that the most favorable mode occurs at a rotor speed of $600 \mathrm{rpm}$. Next, the dependence of the product yield upon SHS grinding of a bulk density sample as a function of the delay time was investigated. The diagram in Fig. 5 shows that the degree of dispersion of the powder for each group of fractional composition is extreme depending on the delay time (Fig. 6).
In the study of the mechanical stressinfluence of on pre-compressed tablets with a relative density of $0.5-0.6$, it was found that the crushed powder consists of agglomerated particles larger than 2-3 mm. The fact is that in the synthesis of a compact work piece, the adhesion strength of the synthesized particles during SHS is higher than for the case with bulk density, and within 1-2 seconds after the start of grinding, the SHS product exhibits increased resistance to shear loads, as a result of which the grinding speed decreases and it is not possible to grind the residue within the limits of the installation. At a rotational speed of the rotor of $240 \mathrm{rpm}$, the remainder was 5-10 mass. \% depending on the delay time. Apparently, by changing the design and technological parameters of the SHS-grinding process for this type of initial billets, it will be possible to achieve a substantial grinding of the powder before it can acquire excessive strength.

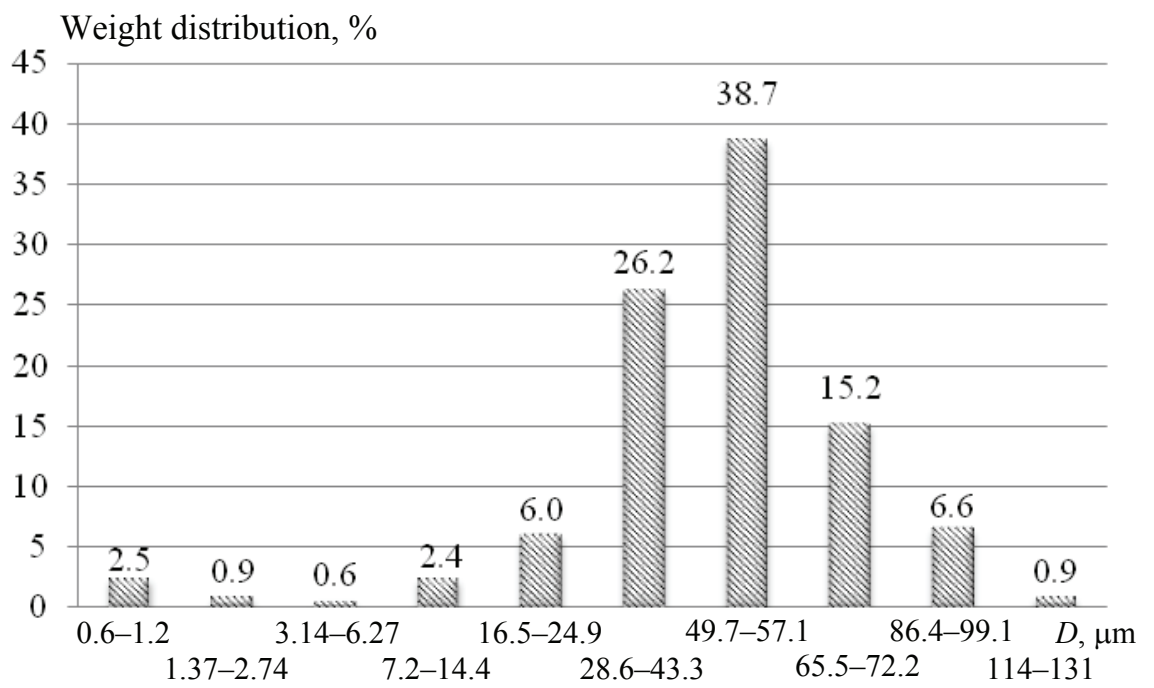

Fig. 4. The dispersion distribution of carbide particles during SHS grinding $\left(600 \mathrm{rpm}, t_{\mathrm{d}}=0 \mathrm{~s}\right)$

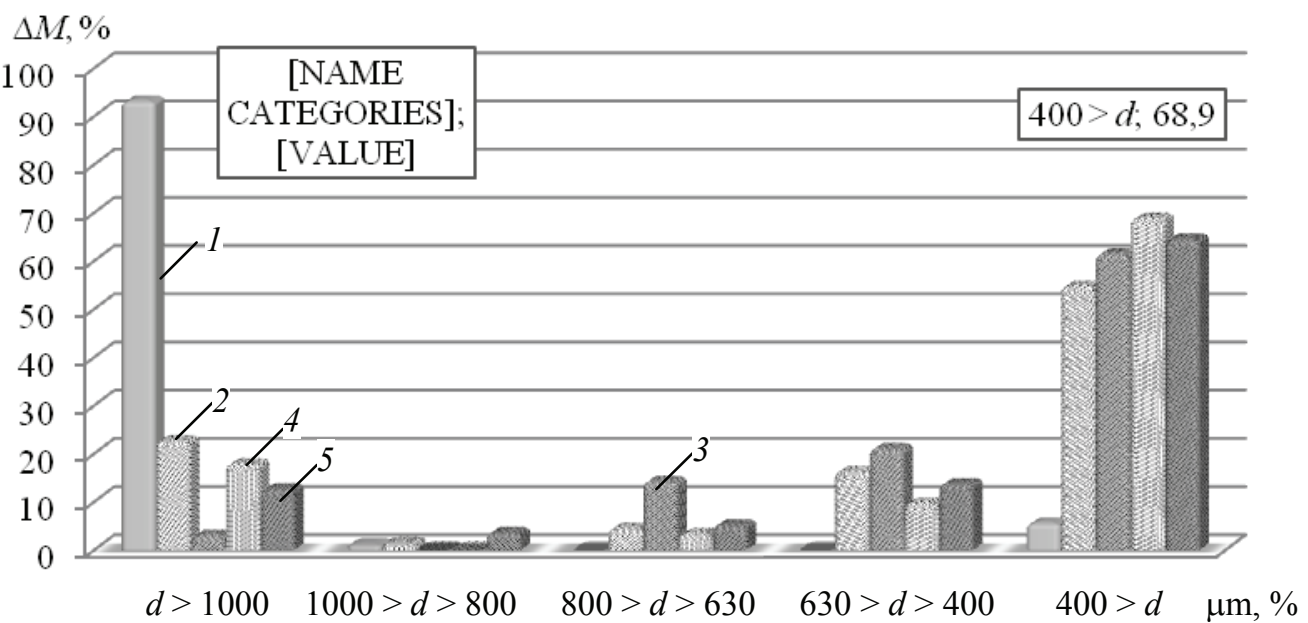

Fig. 5. The dependence of the mass fraction of the yield of crushed product on the delay time at a rotor frequency of $600 \mathrm{rpm}$ : 1 - without mechanical stress application; $2-0 \mathrm{~s} ; 3-5 \mathrm{~s} ; 4-10 \mathrm{~s} ; 5-15 \mathrm{~s}$ 


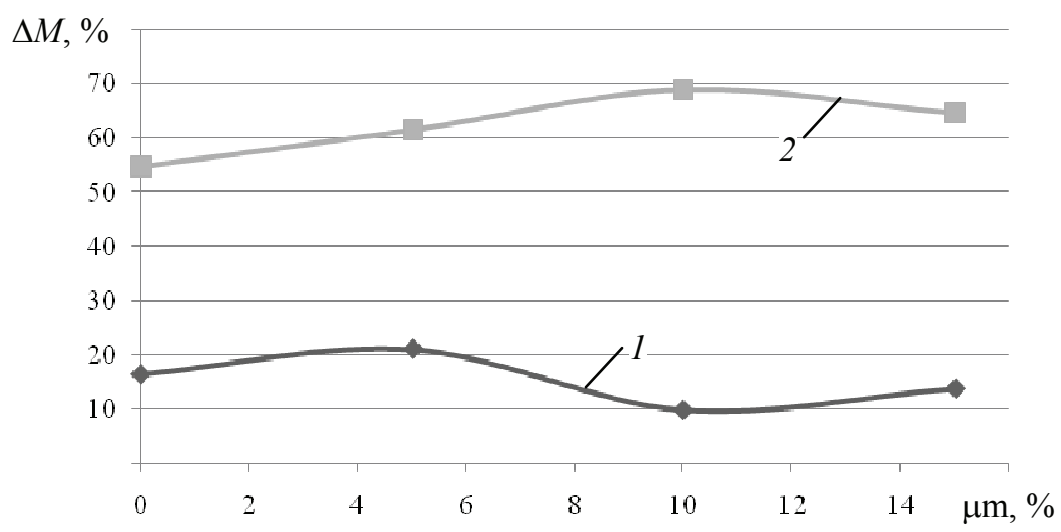

Fig. 6. The degree of dispersion of the crushed fraction of the delay time: $1-630>d>400 ; 2-400>d$

\section{Study of the mechanical stresses influence} on the phase and structure formation of a synthesized material based on $\mathrm{TiC}$

The macrostructure of the synthesized powder without mechanical influences, as well as X-ray spectral analysis over the allocated area are shown in Fig. 7. The characteristic sponge structure of the cake is visible, which is typical for air-cooled aggregates after SHS.

The microstructure of titanium carbide particles synthesized without mechanical influences is represented by sintered particles of a round type with sizes $d>100 \mu \mathrm{m}$. With fragmentation and a larger increase in such a particle, it can be seen that it is a macro volume with pores that are gas removal channels during synthesis (Fig. 8a). The high oxygen content (13 wt. \%) confirms the visible presence of an oxide film on the surface of the cake. The microstructure of carbide particles obtained by mechanical stresses (rotor speed of $450 \mathrm{rpm}$ ) is shown in Fig. 8b. Particles with sizes of 50-60 microns, in contrast to traditional synthesis without mechanical influences, consist of individual carbide particles of round and spongy types with sizes less than 1 micron. Carbide particles of a comminuted structure, characteristic of SHS without mechanical influences, practically do not occur.

An X-ray spectral analysis of the SHS-ground powder over the surface area showed that with an increase in the number of revolutions of the rotor, the content of oxygen impurities decreases from 8.3$13.4 \%$, mass (without mechanical stress) to $1.8-4.6 \%$, mass, when the rotor rotates with a frequency of $450 \mathrm{rpm}$, and up to $1.5-2.8 \%$, masses when the rotor rotates with a frequency of $600 \mathrm{rpm}$ (Fig. 9). A further increase in the rotor speed also intensifies the synthesis of the material and ensures its production with minimal impurities. Thus, the oxygen content in the synthesized material when using mechanical influences is reduced from 3 to 9 times and is at the level of minor impurities (less than $3 \%$ ) with the optimal grinding mode.

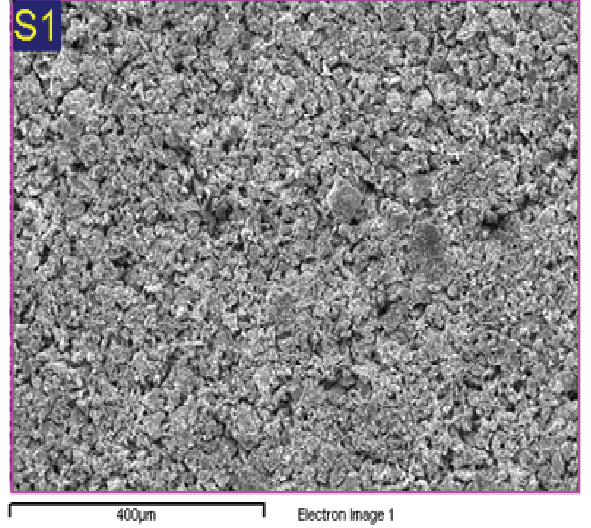

\begin{tabular}{|c|c|c|c|}
\hline Spectrum & $\mathrm{C}$ & $\mathrm{O}$ & $\mathrm{Ti}$ \\
\hline $\mathrm{S} 1$ & 38.46 & 8.31 & 53.22 \\
\hline
\end{tabular}

a)

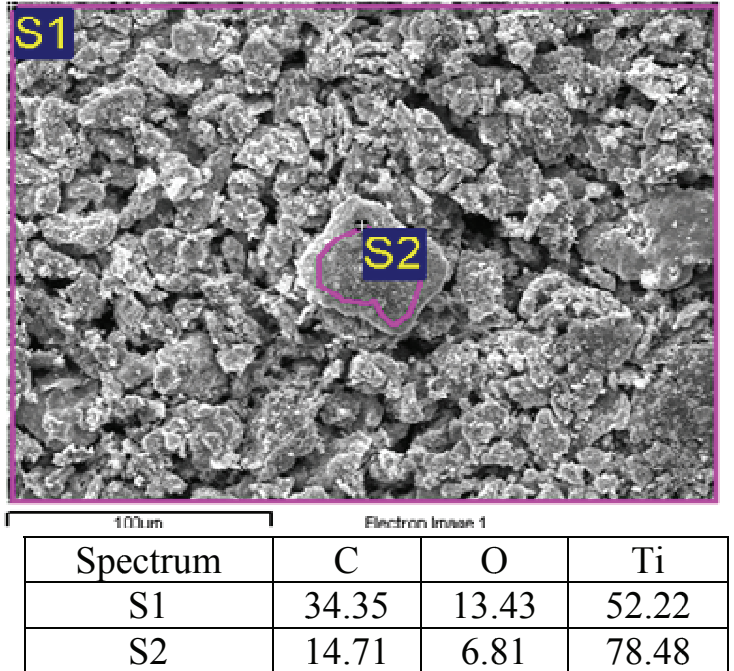

b)

Fig. 7. The macrostructure of the synthesized powder without mechanical influences $(a)$ and $X$-ray spectral analysis of the allocated area $(b)$ 


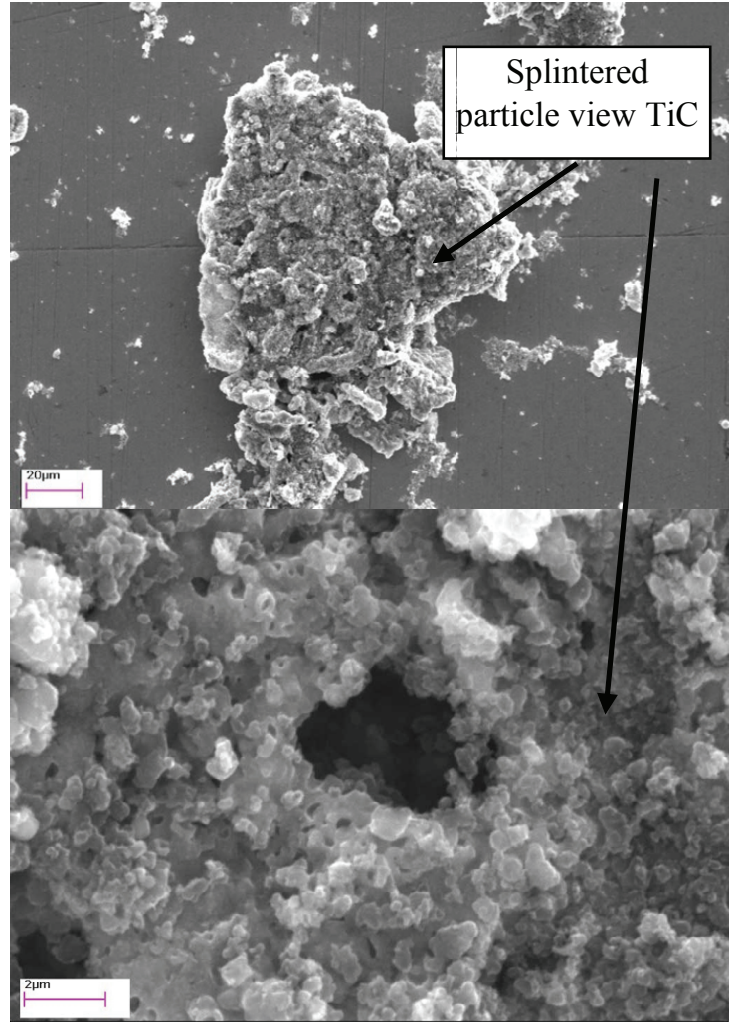

a)

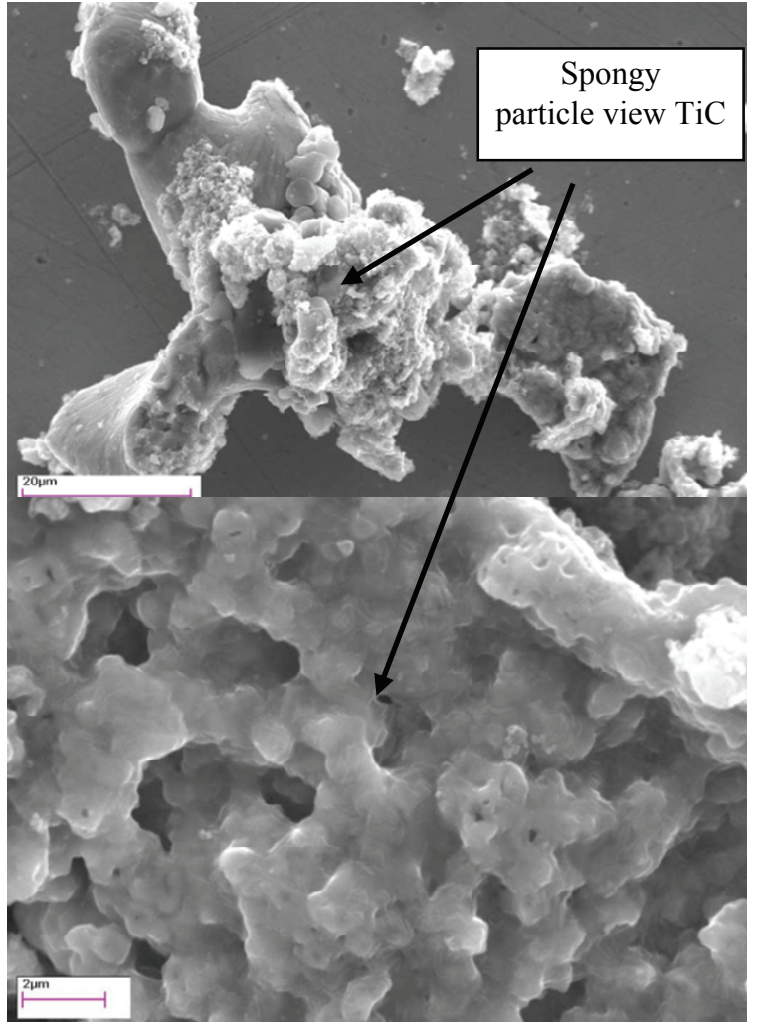

b)

Fig. 8. The microstructure of the synthesized powder: $a$-without mechanical stress; $b$ - with mechanical stress

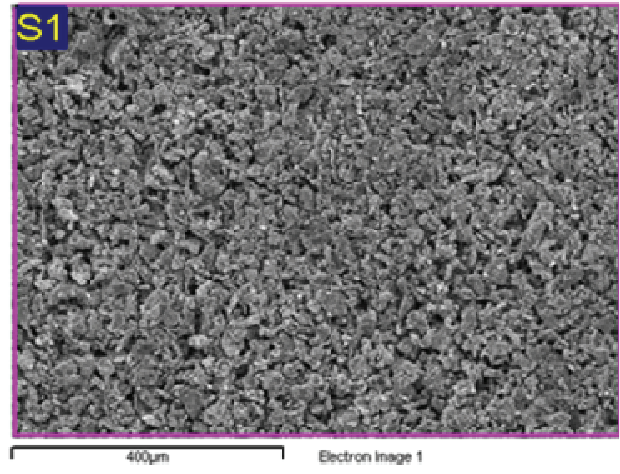

\begin{tabular}{|c|c|c|c|}
\hline Spectrum & $\mathrm{C}$ & $\mathrm{O}$ & $\mathrm{Ti}$ \\
\hline $\mathrm{S} 1$ & 35,05 & 2,83 & 62,12 \\
\hline
\end{tabular}

a)

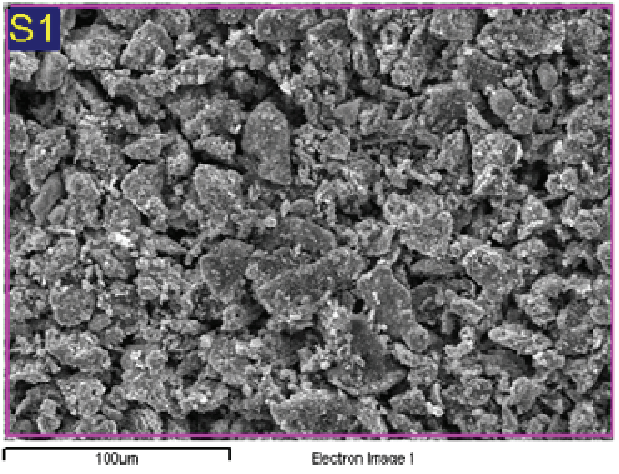

\begin{tabular}{|c|c|c|c|}
\hline Spectrum & $\mathrm{C}$ & $\mathrm{O}$ & $\mathrm{Ti}$ \\
\hline $\mathrm{S} 1$ & 33,71 & 1,48 & 64,82 \\
\hline
\end{tabular}

b)

Fig. 9. The macrostructure of the synthesized powder with mechanical effects and $\mathrm{X}$-ray spectral analysis of the allocated area: $a$ - rotor speed $450 \mathrm{rpm} ; b$ - rotor speed $600 \mathrm{rpm}$

The X-ray phase analysis of the synthesized material was carried out both for cases of SHS-grinding of weights (bulk density), and pre-compressed tablets. In both cases, the only phase is titanium carbide. Moreover, the phase composition does not change with an increase in the delay time before grinding. Fig. 10 shows the X-ray phase analysis of the synthesized materials obtained with a rotor speed of $600 \mathrm{rpm}$ with delay times from 0 to $15 \mathrm{~s}$. It can be seen that the peaks of $\mathrm{TiC}$ intensities overlap each other, which indicates the production of stoichiometric titanium carbide with a crystal lattice with the parameter $a=0.4327 \mathrm{~nm}$, 


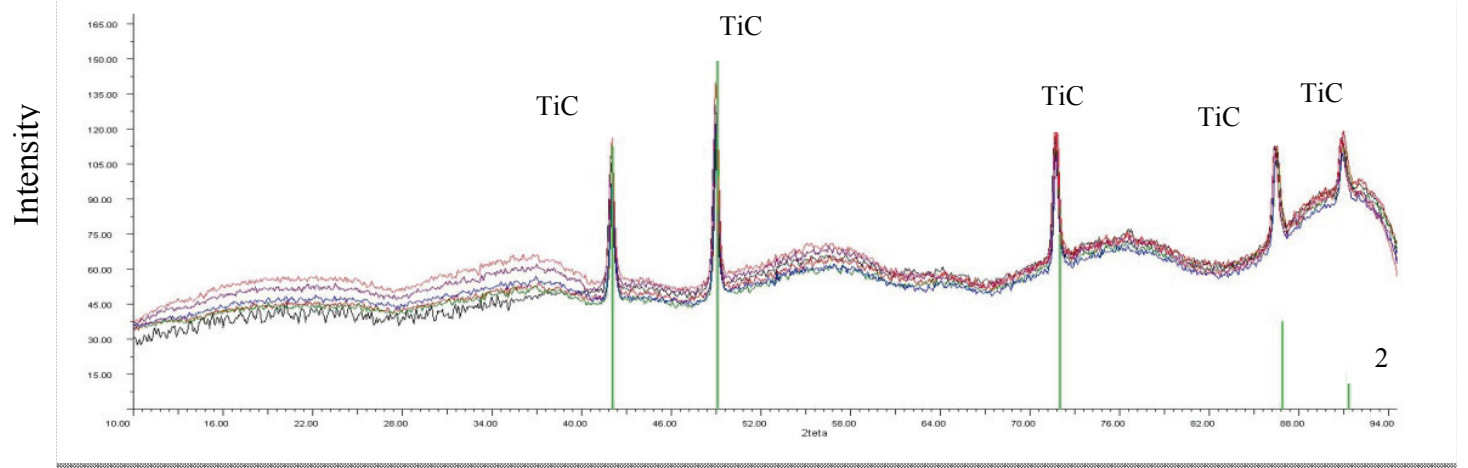

Fig. 10. X-ray phase analysis of ground powder at delay time from 0 to $15 \mathrm{~s}$

regardless of the grinding intensities. The number of oxide inclusions does not exceed 5 mass. \%, while the sinter obtained without mechanical inclusions contains a significant amount of oxide film on the surface (light inclusions).

\section{Conclusions}

The titanium carbide powder was obtained by SHS grinding in a closed reactor with two variants of the initial charge patterns: a bulk density sample and precompressed tablets with a relative density of 0.5-0.6. It was found that in the synthesis without mechanical influences, the synthesized powder consists of a cake of agglomerated particles with sizes of 2-3 mm (more than 70-80 mass. \%). When synthesized in the SHS-grinding mode up to 80 mass. \% powder obtained with a dispersion of $60-70$ microns. It was shown that mechanical effects do not lead to the formation of new phases and do not change the parameters of the crystal lattice, while the content of the oxide phase in the crushed material decreases from 3 to 9 times with increasing intensity of grinding and does not exceed 3 mass. $\%$.

It was shown that mechanical effects during SHS prevent sintering and agglomeration of particles with each other, lead to the destruction of titanium carbide particles sintered during synthesis, favorably affect the morphology and dispersion of the synthesized particles, the amount of impurities, and the yield of the target product. By changing the modes of mechanical stress (rotor type, speed, delay time), the quality of the resulting powder can be improved.

\section{References}

1. Stolin A.M., Stelmakh L.S. Influence of mechanical effects on SHS processes, Abstracts. 2nd French-Russian Workshop on SHS. Villetaneuse. France, 2006, p. 27-28.

2. Stolin A.M., Stelmakh L.S. Vliyaniye deformatsionnykh vozdeystviy na produkty goreniya poristykh poroshkovykh materialov [The influence of deformation effects on the combustion products of porous powder materials], Tezisy VI Minskogo mezhdunarodnogo foruma po teplomassoobmenu, Minsk, Belarus, 2008, 1, 382-383. (Rus)

3. Merzhanov A.G., Munir Z., Holt J.B. Selfpropagating high-temperature synthesis: Twenty years of search and findings, Combustion and Plasma Synthesis of High-Temperature Materials, Eds. Z.A. Munir, J.B. Holt. N.Y.: VCH Publ., 1990, 1-53.

4. Levashov E.A., Mukasyan A.S., Rogachev A.S., Shtansky D.V. Self-propagating high-temperature synthesis of advanced materials and coatings, International Material Review, 2017, 62, 203-239.

5. Bazhin P.M., Stolin A.M., Konstantinov A.S. The Impact of Mechanical Effects on Granulometric Composition of $\mathrm{TiB}_{2}$, Based Materials Adv. Mater. Tech. 2017, 3, 40-43.

6. Stolin A.M., Stelmakh L.S. Mechanisms of Deformation Influences on Combustion products. Abstract book, IX International Symposium on Self-Propagating High - temperature Synthesis. Dijon, France, 2007, 1-5.

7. Stolin A.M., Ponomarev R.N., Stelmakh L.S. Vliyaniye mekhanicheskikh vozdeystviy na izmeneniye prochnosti SVS-produktov pri ikh spekanii I ostyvanii [Influence of mechanical influences on the change in the strength of SHS products during sintering and cooling], Inzhenerno-fizicheskiy zhurnal, 2007, 5, 12-17. (Rus)

8. Stolin A.M. Stelmakh L.S. Influence of deformation factors on the products of combustion of porous powder materials, 2007, 4(50), 1-13. 